PERCEPTION AS A MULTI-STAGE PROCESS: A REIDIAN ACCOUNT

\title{
MARINA FOLESCU
}

University of Missouri

\begin{abstract}
The starting point of this paper is Thomas Reid's anti-skepticism: our knowledge of the external world is justified. The justificatory process, in his view, starts with and relies upon one of the main faculties of the human mind: perception. Reid's theory of perception has been thoroughly studied, but there are some missing links in the explanatory chain offered by the secondary literature. In particular, I will argue that we do not have a complete picture of the mechanism of perception of bodies. The present paper, relying, in part, on a particular theory in psychology - the feature integration theory of attention - will make a contribution in this regard.
\end{abstract}

Keywords: Thomas Reid, philosophy of perception, the feature integration theory of attention, anti-skepticism

\section{INTRODUCTION}

Perception, according to Thomas Reid, is one of the faculties of the human mind on which our knowledge of the external world is based. Although Reid's theory of perception has been studied thoroughly, I submit that a full characterization of his views regarding the mechanism of perception is still missing. In particular, we do not have a good account of how physical bodies are perceived, according to Reid. ${ }^{1}$ My goal here will be to clarify Reid's notion of perception, arguing that his anti-skepticim constrains the way we fill out the details of the picture he offered. ${ }^{2}$

The Journal of Scottish Philosophy 19.1 (2021): 57-74

DOI: $10.3366 /$ jsp.2021.0290

C) Edinburgh University Press

www.euppublishing.com/jsp 
Reid believed that perception is of two kinds: original and acquired. I will side with Van Cleve (2015a), contra Copenhaver (2010), and take it as a given that acquired perception, which is 'the fruit of experience' does not ground our knowledge of the external world; this is the prerogative of 'original' perception only. The main thesis of this paper will be that, for Reid, physical bodies are originally perceived, alongside primary and some secondary qualities. This goes against the standard interpretation of Reid, holding that only primary qualities and maybe one secondary quality - color - are objects of original perception. ${ }^{3}$ Most authors do not explain how bodies are perceived, according to Reid. Van Cleve (2015b) argues that there is an important similarity in the way Reid treats perception of secondary qualities and that of bodies: both types of objects engender 'relative' notions in their perceivers. This leads Van Cleve to say that original perception is restricted to primary qualities only, because our notions of such qualities are direct, a feature that is taken to be a prerequisite for original perception. This interpretation, I will argue, has unwanted consequences for Reid's adherence to and defense of anti-skepticism. My task will be to describe how bodies can be originally perceived, despite our being able to acquire only relative notions of them. ${ }^{4}$ To do so, I will use contemporary research on human vision, specifically, the feature integration theory of attention (FIT, for short).

Before we proceed, a word on methodology. I believe that Reid's theory of perception provides real insights into how one should justify our knowledge of the external world. The fact that his theory does not spell out in needed detail how we have immediate, perceptual access to the external world, with all its qualities, bodies and events, leaves it open to skeptical challenges. This paper will present several characteristics of a contemporary scientific theory which can help us understand how a theory of perception like Reid's should have been developed to more fully account for the mental phenomena under consideration. ${ }^{5}$ The main aim here is to offer as complete a picture of perception as possible. To that effect, one must do two things. First, one must empirically investigate the perceptual mechanism and supply a description of its workings. Second, since, as good Reidians, we are also interested in justification, one must assess the reliability of the mechanism under consideration. By identifying some details that are missing from Reid's picture of perception and by using FIT to start addressing these lacunae, the present paper makes progress on the first of these two issues. ${ }^{6}$ Spelling out the relation between Reid's theory of perception and his reliabilist response to anti-skepticism is a task better left for a future project. ${ }^{7}$

\section{THE ISSUE AND AN OUTLINE OF A SOLUTION}

Reid uses perception to build his case against skepticism relying, primarily, on the following two features: (i) perception is epistemically immediate in the sense 
that the relevant beliefs involved in perception are evident (or justified) without relying on any other beliefs for their justification. ${ }^{8}$ Relatedly, (ii) the knowledge acquired via perception is not the result of learning, experience or reasoning. ${ }^{9}$ I take these features to be normative: only if perception simultaneously satisfies these conditions can Reidian anti-skepticism succeed. My main task is to show that Reidian perception of bodies does conform to these two norms despite the fact that this type of perception turns out to be a process with multiple stages. ${ }^{10}$

What are the reasons for believing that there are multiple stages to perceiving bodies, according to Reid? To elaborate on what I said in my introduction, according to the standard interpretation of Reid, we can perceive secondary qualities only in an acquired manner because our notions of secondary qualities are relative. The standard interpretation entails that bodies are objects of acquired perception, since Reid believes that our perceptual notions of bodies, just like our notions of secondary qualities, are relative. And yet, this entailment is not discussed in the literature. Most everyone seems to think that bodies pose no special problem for original perception. Still: why is it that bodies, which engender relative notions in their perceivers, are not perceived in an acquired fashion? ${ }^{11}$ This issue is philosophically, as well as historically, significant. If we thought that 'relative' were correlated with acquired perception in this way, we would lose a lot of ground to the skeptic: only our knowledge of the primary qualities of bodies - of which we form direct notions - could be perceptually grounded. ${ }^{12}$

I will show that we can originally perceive bodies, despite our being able to have only relative notions of them, just like we can originally perceive color, a secondary quality, despite our being able to have only relative notions of colors. To do so, it will be helpful to understand what our notion of body is relative to. The interpretation I will develop argues that our perceptual notion of body is relative to its qualities, via the sensations we have of them. This reading preserves the epistemic and psychological immediacy of perception, thereby avoiding some of the pitfalls of 'the way of ideas'. ${ }^{13}$

A consequence of this interpretation is that original perception is a process with multiple stages. To fully integrate this result in Reid's theory of perception, we must ensure that perception of bodies displays the two aforementioned normative hallmarks. This paper proposes a way to do so: by drawing on contemporary research on vision.

Some results developed by FIT (Treisman et al. 1977; Treisman 1988) are especially relevant, as I will show in the last section. According to FIT, at the first stage of processing, the visual system registers free-floating features (for example, color, size and shape) and some grouping of features (for example, texture, edges, orientation and boundary information). At the second stage in the model, the visual system breaks down the original input into its constituents. This is followed by the third stage in which the features from the second stage are 
recombined and feature conjunctions are established, resulting in a temporary object representation known as an object file. These stages, according to FIT, are functionally independent and sequential; moreover, the processing from each stage to the next involves no reasoning. Obviously, Reid did not have access to this literature. Nonetheless, I will show that this model is much in the spirit of Reid's theory of perception. I will discuss textual evidence that directly supports the breakdown of human visual processing into three stages, which, I will argue, are analogs of the stages posited by FIT.

\section{THE DIFFERENT STAGES OF ORIGINAL PERCEPTION}

What does it mean to say that original perception, for Reid, is a multi-stage process? Textual evidence indicates that, to have an occurrent perception, a perceiver undergoes the following experiences, sequentially. First, a subject's visual system registers some free-floating qualities and certain conjunctions of such qualities; second, his visual system takes this information apart into its components; and, last, his perceptual system perceives the body to which all of these qualities belong. ${ }^{14}$

The starting point for the current interpretation is Reid's argument that:

[i]t seems to be a judgment of nature, that the things immediately perceived are qualities, which must belong to a subject; and all the information that our senses give us about this subject, is, that it is that to which such qualities belong. From this it is evident, that our notion of body or matter, as distinguished from its qualities is a relative notion. (EIP II.19, 218-219)

Reid holds that by our senses we gain certain information about material substances: they are the things to which the qualities we perceive belong. Additionally, we are told that the notion we have of bodies-derived from perception - is relative to the qualities they are supposed to have. Reid uses 'relative' here as an antonym to 'direct': he believes that perception allows us to form direct notions only of primary qualities. All other notions formed in perception are relative (EIP II.17, 201). Based on this usage, we may conclude that we perceive bodies indirectly. This would, in turn, mean that we do not perceive bodies at all, according to Reid, since, as Van Cleve (2015b: 96) points out, "“indirect" perception [in Reid's view] is an oxymoron. ${ }^{15}$ I reject the conclusion that, according to Reid, we cannot perceive bodies. To develop my interpretation, I will start by positing a seemingly paradoxical premise: we can directly perceive things of which we have only a relative conception. Let us see where this assumption leads us. 
So, how are we to think about this notion of relativity, employed by Reid to describe the process of body perception: what exactly are our perceptual notions of body relative to? As the previous passage indicates, they are relative to their qualities. How, exactly? My suggestion is that sensations play an essential role here: our perceptual notions of bodies are relative to their qualities, via the sensations we have of them. Our sensations of the qualities of a body do double duty: they suggest conceptions and beliefs of the qualities of a particular body and enable our perceptual access to the body itself.

One may worry that the danger of 'the way of ideas' looms large: am I actually saying that sensations - mental entities - are intermediaries of our perception of bodies? Yes, but I do not find this problematic, for a couple of reasons. First, sensations are mental acts without (meaningful) representational content. Reid believes that "[s]ensation is a name given by Philosophers to an act of the mind, which may be distinguished from all others by this, that it hath no object distinct from the act itself" (EIP I.1, 36). We may think this means either that sensations have themselves as objects (Buras 2005) or that sensations have no objects at all (Ganson 2008). Or, as Keating (2019) argues, we may think that we need a paradigm shift to interpret passages like this, given that attributing any type of intentionality to sensations causes more problems than it solves. Regardless of our preferred reading of this passage, the relevant point here is that sensations do not have as objects anything external to the mind. Sensations are not meaningful representatives of external objects. Moreover, sensations are mental acts that are always involved in perception. ${ }^{16}$ If sensations do not interfere with the immediacy of perception in the case of qualities, then they do not interfere with it in the case of bodies either.

Second, Reid is not opposed to specific types of mediation, in particular those involving signs and the things signified:

There is a sense in which a thing may be said to be perceived by a medium. Thus any kind of sign may be said to be the medium by which I perceive or understand the thing signified. The sign ... introduces the thought of the thing signified. But here the thing signified, when it is introduced to the thought, is an object of thought no less immediate than the sign was before. (emphasis added; EIP II. 9, p. 134)

So, it should not matter that sensations are signs that signify perceptions (EIP II.16, 199), thereby mediating our access to the world, as Copenhaver (2004: 71) explains.

There are two main reasons that recommend this reading. First, given that our sensations are not states with intentional content, according to Reid, we have a way of understanding why one can be said to veridically perceive a body, even 
when one perceives one (or more) of its qualities non-veridically. This is due to there being no possibility for having sensorial hallucinations or illusions: ${ }^{17}$

It is impossible that there can be any fallacy in sensation: For we are conscious of all our sensations, and they can neither be any other in their nature, nor greater or less in their degree than we feel them. It is impossible that a man should be in pain, when he does not feel pain; and when he feels pain, it is impossible that his pain should not be real, and in its degree what it is felt to be; and the same thing may be said of every sensation whatsoever. (EIP II.22, 243)

Even when we hallucinate, the sensations accompanying the hallucination are real. When someone has a certain color sensation, even though that color does not exist, his perceptual system is triggered to produce a perceptual representation of a supposed external object. The perceiver, thus, perceives a body, while misperceiving its color, just in virtue of having a sensation of one of its qualities. Even though the perceptual system mistakenly interprets a blue-sensation as an orange one, it also correctly interprets that same sensation as suggesting an external quality, which must belong to a body. The perceiver will be said to have a perception of a colored body even though only an illusion of an orange-colored body. ${ }^{18}$

Second, this option accommodates the idea that perceivers have singular thoughts of bodies, even when they are mistaken in perceptually attributing a certain quality to a body. ${ }^{19}$ Here is how body-perception happens, according to Reid, and the role of sensations in it: once a perceiver has a sensation of a quality, that sensation suggests the quality, which is then conceived of and believed to exist (EIP II.5, 96). The perceiver is now in a position to perceive the body to which the quality belongs: the object now becomes the focus; the properties are effaced and the perceiver turns his attention to the object. The properties, once perceived, are not attended to any longer, when our attention turns to the body itself. According to Reid, attention is necessary for the perception of objects; without attention, some objects do not count as seen (or heard or touched), although they are in the perceiver's field of vision:

When we look at an object, the circumjacent objects may be seen at the same time, although more obscurely and indistinctly: for the eye hath a considerable field of vision, which it takes in at once. But we attend only to the object we look at. The other objects which fall within the field of vision, are not attended to; and therefore are as if they were not seen.

There are many phaenomena of a similar nature, which shew, that the mind may not attend to, and thereby, in some sort, not perceive objects that strike the senses... . I have been assured, by persons of the best skill in music, that 
in hearing a tune upon the harpsichord, when they give attention to the treble, they do not hear the bass; and when they attend to the bass, they do not perceive the air of the treble. (emphasis added; IHM 6.13, 134-135)

This way of describing the process of body-perception above involves two main stages: first, the qualities of a body are perceived, and second, 'attention' comes into play and allows the perceiver to have an 'experience of the unity of the object' (IHM 6.13, 134). Reid did not offer a detailed explanation here or elsewhere of the interplay between perception and attention in the perceptual experience of bodies. A theory like Reid's would benefit from working out these details; I do this in the next section by using some contemporary psychological research. The model I discuss is built on the premise that some aspects of human visual perception are, importantly, object-driven; this is a premise that Reid endorsed.

A word of caution: I will not argue that sensations are features represented in early vision, as understood in the FIT framework. According to FIT, these features are registered unconsciously, whereas Reid believed that 'we are conscious of all our sensations' (EIP II.22, 243). However, Reid did distinguish between conscious and attentive processes and states: '[w]e are conscious of many things to which we give little or no attention' (EIP I.2, 42), which leads Van Cleve (2015b: 24) to emphasize that we can be conscious of something despite our not attending to it. I argue that there is a lot of affinity between Reid's theory and FIT on this score: the early stages of vision are thought to be pre-attentive by both theories. Moreover, attention seems to be needed for body perception. In the next section, I discuss FIT to try to elucidate Reid's metaphor of 'suggestion', used by him to describe how our minds move from sensing (and, thus, registering information about) the world to actually representing it in perception (IHM 6.21, 177).

\section{LESSONS FROM THE PSYCHOLOGICAL LITERATURE ON BINDING}

In the following sections, we will look at a model that describes in detail the several stages of visual perception. ${ }^{20} \mathrm{I}$ will argue that the psychological findings discussed here provide a natural way to understand how a philosophical theory like Reid's could have been scientifically supported. Given that Reidian perception is a process with multiple stages, it is natural to inquire what are these stages and how they are connected. I believe that FIT can help us understand how bodies are originally perceived.

\subsection{The Feature-Integration Theory of Attention}

The 'feature-integration theory of attention' (FIT) describes how visual perception of objects works. There are two main points of connection with 
Reid: first, FIT offers experimental evidence to show that there is an important difference between the process of detecting qualities and the process of binding these qualities to an object-representation, known as an 'object-file'. ${ }^{21}$ As Folescu (2015: 27-28) points out, such a distinction does some work in Reid's theory (EIP II.19, 219). Second, FIT recognizes the role of attention in holding the representations of features together.

To begin, several experiments conducted on typical participants showed that they register features and some initial conjunction representations in early vision. Before participants represent objects from their environment, they go through an intermediary stage, at which the input from the first stage is decomposed in its constitutive parts: a small set of individual features of objects now become available to perceivers. All the features identified by Treisman (1998) as belonging to the first stage are features that Reid also believed to be originally perceived in vision: all the primary qualities of objects and color, a secondary quality.

According to FIT, objects in the participants' environment, together with their settings, are identified at the third stage of visual perception. Once basic features are registered via the first and second stages of perception, they are then 'bound' or attributed to an object. The third stage is a stage of recombination: the perceptual mechanism establishes feature conjunctions via the process of feature integration. These newly formed conjunctions are represented within an object file. These conjunctions support and maybe enable conscious perception (Quinlan 2003: 650). Moreover, attending to one or a couple of features may enable our perceptual mechanism to select the whole object, as Schoenfeld et al. (2014: 619) explain.

I would like to draw the following observations. First, these stages are ordered and interdependent: the first stage can operate correctly, independently of the other two; the second, however, cannot operate in the absence of the first one, and the third cannot operate in the absence of the first and the second. This is supported by evidence from patients with certain types of brain injuries. In particular, the case of patient R. M. is illustrative here: while he could easily identify multiple unbound features, he could not do the same either with conjunctions of two or more features or with objects. He could only see one object at a time. ${ }^{22}$ This observation is well-aligned with Reid's belief that there exists a metaphysical asymmetry between objects and their qualities: objects 'have' qualities, but qualities do not 'have' objects; qualities 'belong' to such things. Moreover, one of the main functions of perception seems to be that of selecting objects. ${ }^{23}$

Second, even though visual perception is a process with multiple stages, the mental processing involved in moving from one stage to the next does not involve reasoning (Treisman 1998: 399). This aspect of FIT is very important to a Reidian. 


\subsection{Evidence for FIT: The Binding Problem}

Integrating features perceived at pre-attentive stages into wholes, at later stages, is not unique to perception. The human mind comes equipped with great associative powers. Nonetheless, psychologists have been trying to understand why perception and associated automatic processes help us 'respond to relations to relevant subsets of the world, but not to relations between arbitrarily selected parts or properties' (Treisman 1999: 105). It is difficult for the perceptual system to correctly determine which features belong to which objects in a visual scene that usually contains more than one object. This is commonly referred to as 'the binding problem'. Understanding what types of binding errors can arise helps explain why certain features are combined by the human mind into meaningful wholes, while others are not. ${ }^{24}$

Our visual perceptual system must always solve, and is usually successful at solving, the binding problem. This is taken as evidence that features are bound to objects at later stages of visual processing. It is alleged that simultaneously processing features and the objects they belong to would allow for smooth integration of features into meaningful wholes. Certain errors are quite common, which entails that our visual system processes features before processing the objects they belong to. In particular, illusory conjunctions, extensively studied by the proponents of FIT, are relevant here.

Patients with certain brain injuries are very susceptible to illusory conjunctions. In experimental lab settings, participant R. M., who had suffered damage to both sides of his occipito-parietal cortex, was unable to correctly 'bind simultaneously presented features' to more than one object at a time (Treisman 1999a: 100). R. M. would incorrectly attribute the color of one of the objects to one of the other objects presented in the display, thus obtaining a conjunction of features and objects that did not exist in the real world (Treisman 1999a: 94).

Importantly, it is not only people who have suffered traumatic brain injuries that are prone to such binding errors. Treisman and Schmidt (1982) proposed certain experiments to show that typical participants are susceptible to illusory conjunctions of features too. In one such experiment, participants were presented with a display showing a line of colored shapes or letters, flanked by two black digits. They were asked to report what the two digits were, so that they would not pay close attention to the colored shapes. Participants reported correctly what the digits were, but the reports of the stimuli between the two digits were inaccurate and showed that the participants were susceptible to a large number of illusory conjunctions. It was irrelevant whether the stimuli between the two digits were letters or shapes; the participants reported illusory conjunctions regarding all the features tested - that is, color, shape, size and solidity. The conclusions drawn from such experiments were not based solely on the verbal reports of the participants but also on simultaneous and successive matching tasks, thus, 
indicating that these errors are neither failures of memory nor of verbal labeling (Treisman and Schmidt 1982: 138).

The existence of illusory conjunctions of features, especially in typical perceivers, indicates that features are separately coded by the perceptual mechanism, since otherwise there would be no reason to explain why it is possible to recombine them incorrectly. This tendency to form illusory conjunctions by recombining features which characterize separate objects supports the idea that our visual perception starts by perceiving features and then moves to perceiving conjunctions of features and, at a later stage, objects (Treisman 1999a: 96-97)). ${ }^{25}$

There is no discussion of a 'binding problem', as such, in Reid. This is not surprising since psychologists introduced this term of art in the twentieth century. The phenomenon of illusory conjunctions, however, was known to Reid:

As in certain circumstances we invariably see one object appear double, so in others we as invariably see two objects unite into one; and, in appea rance, lose their duplicity. This is evident in the appearance of the binocular telescope. And the same thing happens when any two similar tubes are applied to the two eyes in parallel direction; for in this case we see only one tube... . If two pieces of coin, or other bodies, of different colour, and of different figure, be properly placed in the two axes of the eyes, and at the extremities of the tubes, we shall see both the bodies in one and the same place, each as it were spread over the other, without hiding it; and the colour will be that which is compounded of the two colours. (IHM 6.13, 136)

In the first example, we are presented with a type of illusory conjunction that is different from the ones talked about in the psychological literature nowadays. Two different objects are processed as one: thus, all features of the two objects are bound by the visual system to a single object; all these features are placed into a single object file, instead of two. The next example is more akin to the ones Treisman and her colleagues talk about. In this instance, we have a case in which locations and colors are not correctly attributed to their respective objects. The visual system creates an illusory conjunction: a single location and a single color are combined and bound to a single object.

In other places, Reid argues that the same color can be localized at different positions on the visual field:

The object makes an appearance to each eye, as the sound makes an impression upon each ear; so far the two senses [vision and hearing] agree. But the visible appearance may be distinguished by place, when perfectly like in other respects; the sounds cannot be thus distinguished; and herein the two senses differ... . [W] [Wen [the two appearances] have not the same visible place, they are perfectly distinguishable, and we see the object double. (IHM 6.17, $153-154)$ 
Falkenstein (2000: 318 ) believes that this indicates that 'the same colour is associated with different positions'. This helps Reid account for the case of double vision - a paradigm case of illusory conjunctions. I would add to this that Reid's discussion of these data is anticipating the contemporary discussion of the errors patient R. M. was noticed to make consistently.

This evidence indicates that it is legitimate to attribute to Reid a theory that is closely resembling FIT. The result is that human perception is a multi-stage process. The processing between these stages is automatic and non-inferential. Reid's anti-skepticism is not, therefore, under attack.

\subsection{The Object-driven Character of Human Visual Perception}

Visual perception, on the model proposed by FIT, is, importantly, object-driven: the pre-attentive stages supply the necessary materials to ensure that objects are perceived. It is the third, attentive stage of perception that is responsible for our actually perceiving extant objects, when the features coded at the pre-attentive stages are correctly bound to a representation of an object. On the current model, one can perceive an object even in the absence of veridical perception of its qualities. The existence of illusory conjunctions indicates that visual perception starts with qualities of objects but ends with objects, thus emphasizing the singular character of our perceptual thoughts.

Psychologists argue that motion tracking experiments provide evidence that perception is object-driven. ${ }^{26}$ Kahneman et al. (1992) observed that, as long as our attention is guided by those features that control the unity and continuity of an object over a certain interval of time, that object will be perceived as the same object even though some of its qualities are seen to change over that interval of time. For instance, an object can be seen to change its shape and color and still be perceived as the same object, as long as its continuity is not broken down (Kahneman et al. 1992: 217). Concretely, people watching a Superman movie will say things like: 'It's a bird; it's a plane; it's Superman!' without registering any change of referent for the pronoun 'it'. They see and talk about a single object, initially thought to be a bird, then a plane, then Superman.

In $I H M$, Reid presents a similar case:

Walking by the sea-side in a thick fog, I see an object which seems to me to be a man on horseback, and at the distance of about half a mile. My companion, who has better eyes, or is more accustomed to see such objects in such circumstances, assures me, that it is a sea-gull, and not a man on horseback. Upon a second view, I immediately assent to his opinion; and now it appears to me to be a sea-gull, and at the distance only of seventy or eighty yards $(I H M 6.22,183)$. 
The one and only object of perception in Reid's story first appeared to him as a man on horseback, and then as a sea-gull. Despite these different appearances, the pronoun 'it' refers to the same thing throughout, even though there is a considerable conceptual distance between a man on horseback and a seagull. Importantly, Reid thinks that perception supplies these two very different characterizations of the same object, not a faculty involving reasoning:

The mistake made on this occasion, and the correction of it, are both so sudden, that we are at a loss whether to call them by the name of judgment, or by that of simple perception.

It is not worth while to dispute about names; but it is evident, that my belief, both first and last, was produced rather by signs than by arguments and that the mind proceeded to the conclusion in both cases by habit, and not by ratiocination (IHM 6.22, 183-184).

So, according both to Reid and contemporary psychologists, visual perception can work in such a way that, if certain spatiotemporal conditions are met, an object will be perceived as a single object, even when it undergoes some radical apparent changes.

To explain this phenomenon, proponents of FIT argue that our visual system selects the features that are most active in the visual segmentation process and suppresses "those in other locations to prevent erroneous bindings. The selected features are combined to form an "object token".' (Treisman 1996: 172). This object token, more commonly known as an 'object file', is a representation of an object, where its features, observed at the pre-attentive stage, are coded, stored and updated. To employ an analogy, perception operates like a police investigation: the police open a file where information on the crime is collected and updated. Similarly, perception facilitates the opening of a mental file, where all the perceptual information about a particular object is entered, updated and stored (Treisman 1998: 410).

This, then, is the complete model of visual perception: our visual system selects qualities; this leads to the opening of an object file; some changes and updates can be made to that file, so long as certain spatiotemporal constraints are satisfied. Once the object file is established, perception picks out the object itself, while its qualities remain in the background. On this picture, de re perceptions are possible, even though, to speak Reid's language, the perceptual conception of the object, and, hence, the perception itself, is relative to the sensations of the object's qualities.

\section{CONCLUSION}

This paper discussed how to best understand the mechanism of (visual) perception of bodies, given Reid's theory of perception. I started by clarifying what our 
notions of objects might be relative to, in Reid's view, keeping in mind his general anti-skeptical stance. It turned out that the notions of bodies we have in perception are relative to the qualities of those bodies, via the sensations we have of those qualities. Consequently, perception of bodies is a multi-stage process: the first stage is dedicated to identifying and selecting qualities of objects, while the following stage(s) are dedicated to perceiving the objects having those qualities.

The last sections discussed a possible way of understanding how visual perception of bodies can be a multi-stage process. According to this model, known as 'the feature integration theory of attention', human visual perception has several stages: (i) a pre-attentive stage, in which features of objects, and certain conjunctions of features, are selected from the visual field, (ii) a stage at which the features are processed and divided into their components, and (iii) an attentive stage, in which the features selected at the first stage, and processed at the second, are bound to a single object.

If the arguments and analyses presented here are correct, Reid's theory of perception is more modern than initially thought, by aligning itself with contemporary research on vision theory and perception.

\section{REFERENCES}

Antony, L. (2004) 'A Naturalized Approach to the A Priori', Philosophical Issues 14: 1-17. Atherton, M. (1984) “'Suppose I am Pricked with a Pin”: Locke, Reid and the Implications of Representationalism', Pacific Philosophical Quarterly 65(2): 149-165.

Beanblossom, R. E. (1975) 'In Defence of Thomas Reid's Use of Suggestion', Grazer Philosophische Studien 1: 53-62.

Ben-Zeev, A. (1986) 'Reid's Direct Approach to Perception', Studies in History and Philosophy of Science 17: 99-114.

Bergmann, M. (2008) 'Reidian Externalism', in Vincent Hendricks and Duncan Pritchard (eds), New Waves in Epistemology, New York: Palgrave, pp. 52-74.

Buras, T. (2005) 'The Nature of Sensations in Reid', History of Philosophy Quarterly 22(3): 221-238.

(2008) 'Three Grades of Immediate Perception: Thomas Reid's Distinctions', Philosophy and Phenomenological Research 76(3): 603-632.

(2009) 'The Function of Sensations in Reid', Journal of the History of Philosophy 47(3): 329-353.

Chan, L. K. H. and W. G. Hayward (2009) 'Feature Integration Theory Revisited: Dissociating Feature Detection and Attentional Guidance in Visual Search', Journal of Experimental Psychology: Human Perception and Performance 35(1): 119-132.

Chappell, V. (1989) 'The Theory of Sensations,' in M. Dalgarno and E. Matthews (eds), The Philosophy of Thomas Reid, Dordrecht: Kluwer, pp. 49-63.

Copenhaver, R. (2000) 'Thomas Reid's Direct Realism', Reid Studies 4(1): 17-34.

— (2004) 'A Realism for Reid: Mediated but Direct', British Journal for the History of Philosophy 12(1): 61-74.

(2010) 'Thomas Reid on Acquired Perception', Pacific Philosophical Quarterly 91(3): 285-312. 
(2016) 'Additional Perceptive Powers: Comments on Van Cleve's Problems from Reid', Philosophy and Phenomenological Research 93(1): 218-224.

de Bary, P. (2002) 'Thomas Reid And Scepticism: His Reliabilist Response', New York: Routledge.

Duggan, T. (1960) 'Thomas Reid's Theory of Sensation', Philosophical Review 69: 90-100.

Duncan, J., and G. W. Humphreys (1989) 'Visual Search and Stimulus Similarity', Psychological Review 96: 433-458.

- (1992) 'Beyond The Search Surface: Visual Search and Attentional Engagement', Journal of Experimental Psychology: Human Perception and Performance 18: $578-588$

Dyson, B. J. and P. T. Quinlan (2003) 'Feature And Conjunction Processing In The Auditory Modality', Perception and Psychophysics 65: 254-272.

Falkenstein, L. (2000) 'Reid's Account of Localization', Philosophy and Phenomenological Research 61: 305-328.

Falkenstein, L. and G. Grandi (2003) 'The Role Of Material Impressions In Reid's Theory Of Vision: A Critique Of Gideon Yaffe's 'Reid On The Perception Of Visible Figure', Journal of Scottish Philosophy 1(2): 117-133.

Folescu, M. (2015) 'Perceiving Bodies Immediately: Thomas Reid's Insight', History of Philosophy Quarterly 32(1): 19-36.

Ganson, T. (2008) 'Reid's Rejection of Intentionalism', Oxford Studies in Early Modern Philosophy 4: 245-263.

Green, M. (1992) 'Visual Search: Detection, Identification and Localization', Perception 21: 765-777.

Immerwahr, J. (1978) 'The Development of Reid's Realism', The Monist 61(2): 245-256.

Kahneman, D., A. Treisman, and B. J. Gibbs (1992) 'The Reviewing of Object Files: Object-specific Integration of Information', Cognitive Psychology 24: 175-219.

Keating, L. S. (2019) 'Reid on Conception and Object-Directedness: Moving Beyond the Framework of Intentionality', Journal of the History of Philosophy 57(1): 81-105.

Koivisto, M., and J. Silvanto (2012) 'Visual Feature Binding: The Critical Time Window Of V1/V2 And Parietal Activity', Neuroimage 59: 1608-1614.

Lehrer, K. (1989) Thomas Reid, New York: Routledge.

Lehrer, K. and J. C. Smith (1985) 'Reid on Testimony and Perception', in D. Copp, and J. J. MacIntosh (eds), 'New Essays in Philosophy of Mind. Series II', Canadian Journal of Philosophy, vol. suppl. 11: 21-38.

Murray, M. M. and C. S. Herrmann (2013) 'Illusory Contours: A Window Onto The Neurophysiology Of Constructing Perception', Trends in Cognitive Sciences 17(9): 471-481.

Nichols, R. (2007) Thomas Reid's Theory of Perception, Oxford: Oxford University Press.

Pappas, G. S. (1989) 'Sensation and Perception in Reid', Noûs 23(2): 155-167.

Pylyshyn, Z. W. (1989) 'The Role of Location Indexes in Spatial Perception: A Sketch of the FINST Spatial Index Model', Cognition 32: 65-97.

Quilty-Dunn, J. (2013) 'Reid on Olfaction and Secondary Qualities', Frontiers in Psychology 974(4).

Quinlan, P. (2003) 'Visual feature integration theory: Past, present, and future', Psychological Bulletin 129(5): 643-673.

Reid, T. [1764] (1997) An Inquiry into the Human Mind on the Principles of Common Sense, ed. D. R. Brookes, Edinburgh: University Press.

[1785] (2002) Essays on the Intellectual Powers of Man, eds D. R. Brookes and K. 50 Haakonssen, Edinburgh: University Press. 
Sagi, D. and B. Julesz (1985) "“Where" and "What" In Vision', Science 228(4704): 1217-1219.

Schoenfeld, M. A., J. M. Hopf, C. Merkel, H. J. Heinze, and S. A. Hillyard (2014) 'ObjectBased Attention Involves The Sequential Activation Of Feature-Specific Corticle Modules', Nature Neuroscience 17(4): 619-626.

Scholl, B. J. (2001) 'Objects and attention: The State of the Art', Cognition 80: 1-46.

Shrock, C. A. (2017) Thomas Reid and the Problem of Secondary Qualities, Edinburgh: Edinburgh University Press.

Thorpe, L. (2015) 'Seeing White And Wrong: Reid On The Role Of Sensations In Perception, With A Focus On Colour Perception', in R. Copenhaver and T. Buras (eds), Thomas Reid on Mind, Knowledge, and Value: Essays in Honor of Reid's Tercentenary, Oxford: Oxford University Press, pp. 100-123.

Treisman, A. (1988) 'Features and Objects: The Fourteenth Bartlett Memorial Lecture', The Quarterly Journal of Experimental Psychology 40(2): 201-237.

(1991) 'Search, Similarity and Integration of features between and within dimensions', Journal of Experimental Psychology: Human Perception and Performancerception and Performance 17: 652-676.

(1992) 'Spreading Suppression Of Feature Integration? A Reply To Duncan and Humphreys (1992)', Journal of Experimental Psychology: Human Perception and Performance 18: 589-593.

(1996) 'The Binding Problem', Current Opinion in Neurobiology 6: 171-178.

(1998) 'Features and Objects in Visual Processing', in G. Mather, F. Verstraten, and S. Anstis (eds), The Motion Aftereffect, Cambridge, Mass.: MIT Press, pp. 399-413. (1999a) 'Feature Binding, Attention and Object Perception', in J. G. W. Humphreys (ed.), Attention, Space and Action, Oxford: Oxford University Press, pp. 91-111. (1999b) 'Solutions to the Binding Problem: Progress Through Controversy and Convergence', Neuron 24: 105-110.

Treisman, A., and G. Gelade (1980) 'A Feature-Integration Theory of Attention', Cognitive Psychology 12: 97-136.

Treisman, A., and H. Schmidt (1982) 'Illusory Conjunctions in the Perception of Objects', Cognitive Psychology 14: 107-141.

Treisman, A., M. Skyes, and G. Gelade (1977) 'Selective Attention and Stimulus Integration', in S. Dornic (ed.), Attention and Performance VI, Hillsdale, NJ: Lawrence Erlbaum, pp. 333-361.

Van Cleve, J. (2004) 'Reid's Theory of Perception', in T. Cuneo and R. Van Woudenberg (eds), The Cambridge Companion to Reid, Cambridge: Cambridge University Press, pp. 101-133.

(2015a) 'Four Questions About Acquired Perception', in R. Copenhaver and T. Buras (eds), Mind, Knowledge, and Value: Essays in Honor of Reid's Tercentenary, Oxford: Oxford University Press, pp. 75-99.

(2015b) Problems from Reid, Oxford: Oxford University Press.

Van Woudenberg, R. (2013) 'Thomas Reid between Externalism and Internalism', Journal of the History of Philosophy 51(1): 75-92.

Wolfe, J. M. (2003) 'Moving Towards Solutions to Some Enduring Controversies in Visual Search', Trends in Cognitive Sciences 7(2): 70-76.

Wolterstorff, N. (2000) 'Thomas Reid's Account of the Objectivated Character of Perception', Reid Studies 4(1): 3-16.

Yaffe, G. (2003a) 'The Office of an Introspectible Sensation: A Reply to Falkenstein and Grandi', Journal of Scottish Philosophy 1(2): 135-140.

(2003b) 'Reid on the Perception of Visible Figure', Journal of Scottish Philosophy 1(2): 103-115. 
Zmigrod, S. and B. Hommel (2009) 'Auditory Event Files: Integrating Auditory Perception And Action Planning', Attention, Perception, and Psychophysics 71: 352-362.

(2013) 'Feature Integration Across Multimodal Perception And Action: A Review', Multisensory Research 26: 143-157.

\section{NOTES}

${ }^{1}$ The literature on Reid's theory of perception is extensive, addressing and solving several key issues. However, there are not many accounts that explain how exactly we perceive all of the following: primary qualities, secondary qualities, and bodies. Some authors, for example, Buras (2009), Nichols (2007), and Lehrer and Smith (1985), argue that only primary qualities can be originally perceived, while secondary qualities are, at most, objects of acquired perception. Others, like Falkenstein (2000), note that such an interpretation is incorrect, since only the perception of the location of secondary qualities is acquired. In the same vein, Van Cleve (2015a; 2015b) argues that at least some secondary qualities can be originally perceived. Still others assume that bodies can be objects of original perception without explaining how exactly this comes about, for example, Copenhaver (2004) and Folescu (2015).

2 Although independent, the psychology of perception is not orthogonal to epistemology, since certain psychological theories make skepticism harder to avoid, according to Reid. For a comprehensive discussion of Reid's anti-skepticism, see Lehrer (1989), de Bary (2002), and Van Woudenberg (2013).

${ }^{3}$ Proponents of 'the standard interpretation' are: Lehrer and Smith (1985), Nichols (2007), Buras (2009), Copenhaver (2010), and Van Cleve (2015b). For an interesting departure from this view, according to which all secondary qualities are, indeed, objects of original perception, see Shrock (2017).

${ }^{4}$ Several key passages support this reading: IHM 6.20, 167-168; EIP II.14, 172 and II.19, 217. IHM = Thomas Reid, An Inquiry into the Human Mind on the Principles of Common Sense; EIP = Thomas Reid, Essays on the Intellectual Powers of Man.

${ }^{5}$ My choice of FIT, rather than a competing theory of visual perception, is determined by several reasons. Although it is true that FIT has been contested in the literature, this is par for the course in the sciences: usually, the data are open to interpretation and, in this case, as Treisman (1992) points out, FIT's dissenters have not really proposed better alternatives for explaining all data. For the purposes of this paper, FIT provides an account that does justice to a system like Reid's, without forcing it to adjust to its findings. It acknowledges the metaphysical asymmetry between objects and their qualities. Other theories might do this too; it is important, however, to acknowledge that FIT is able to preserve this essential feature of the Reidian system. Furthermore, FIT's explanatory power is wide-ranging: as Zmigrod and Hommel (2013: 153) point out, the same process that leads to the formation of object files seems to be employed for the formation, updating, and retrieval of event files (for example, auditory event files: Zmigrod and Hommel (2009)). FIT, thus, shows promise in explaining complex mental phenomena, beyond vision, such as the integration of multimodal features, across perception and action. Finally, support for FIT comes from different (related) disciplines: experimental psychology (Kahneman et al. (1992)) and neuroscience (Koivisto and Silvanto 2012; Murray and Herrmann 2013).

${ }^{6}$ Notably, neither Reid nor FIT is interested in providing an explanation of why the phenomena discussed arise in the particular way they do. Their goal is to describe them as completely as possible. Doing so, Reid believes, will answer important skeptical challenges. 
${ }^{7}$ Antony (2004: 12-15) explains why these desiderata must be met for a reliabilist theory of justification. Some readers might not necessarily agree with this reliabilist reading of Reid, proposed, primarily by de Bary (2002). It is possible, indeed, for justification to be relegated to the proper functioning of perceptual faculties or even to the psychological irresistibility of mental operations instead (see, for instance, the details of Reidian externalism discussed in Bergmann (2008)). I am siding with de Bary's interpretation in this paper. I thank an anonymous referee for this journal for bringing this issue to my attention.

8 The notion of 'immediacy' in Reid's work is fully explicated in Pappas (1989), Buras (2008), and Van Cleve (2015b). Throughout this paper, I will work mostly with immediacy in the psychological sense, characterized by feature (ii) in the main text (see also, the characterization offered by Van Cleve (2015b: 13)).

${ }^{9}$ See Van Cleve (2015a) for a detailed explanation why Reidian original perception has these two features.

${ }^{10}$ The existence of these stages has not been identified before, even though commentators have noted that Reidian perception involves a causal chain. This paper adds to the findings regarding this issue, found in: Duggan (1960), Beanblossom (1975), Atherton (1984), Ben-Zeev (1986), Chappell (1989), Pappas (1989), Copenhaver (2000), Van Cleve (2004) and Buras (2009).

${ }^{11}$ Other authors have noticed that, in the secondary literature, secondary qualities get the short end of the bargain. Thorpe (2015), for instance, argues, correctly in my view, that this is due to a misplaced emphasis on Reid's claim that secondary qualities engender only relative notions in their perceivers. Thorpe's reading, however, does not account for the fact that both secondary qualities and bodies are 'literally perceived', according to Reid. This, I believe, requires further discussion.

12 This observation is related to one made in Quilty-Dunn (2013) about secondary qualities: 'Reidian acquired perception enables genuine olfactory perceptual acquaintance with odors despite the dependence of the semantic properties of the relevant representations on causal relations to sensations.' Quilty-Dunn offers this as a solution that explains how a secondary quality - odor - can be perceived. That solution is not supposed to cover the case of perception of bodie,s and it is unclear to me that that particular explanation can be easily generalized.

${ }^{13}$ Almost everyone interested in Reid's theory of perception recognizes the special role played by sensations in the chain of perception. Several authors, such as Immerwahr (1978), Pappas (1989), and Wolterstorff (2000), have raised the worry that Reid's appeal to sensations makes him a representative of indirect realism, something that Reid would have opposed, given his over-arching anti-skeptical concerns. Copenhaver (2004) offers compelling reasons to dispel this worry.

${ }^{14}$ A word of clarification: Reid didn't distinguish between personal and sub-personal systems; I will use this distinction, however, for precision's stake.

15 Van Cleve (2015b: 154) points out that Reid's text is genuinely inconsistent concerning the perception of bodies: sometimes he writes that we perceive bodies: IHM 6.20, 167-168; EIP II.14, 172; EIP II.19, 217. Other times, he writes that we do not: EIP I.2, 43; EIP II.17-18.

${ }^{16}$ According to Yaffe (2003b), even our perception of visible figure is based on a sensation of a quality, albeit the quality in question is not visible figure, but color. This is the only case in which the sensation of a quality suggests the conception and belief of the existence of a different quality, according to Reid $(I H M 6.8,99)$. This is a controversial interpretative point. Falkenstein and Grandi (2003) argue for the opposite view: the perception of visible figure requires no sensation. For my part, I side with the arguments 
in Yaffe (2003b) and in Yaffe (2003a). As Falkenstein (2000) himself points out, Reid seems to hold genuinely contradictory views on this issue.

${ }^{17}$ I side with Copenhaver (2016: 219) who argues that sensations are primarily sensory registrations.

${ }^{18}$ In connection with this type of phenomenon, Reid discusses cases of phantom limb pain (EIP II.18, 214).

${ }^{19}$ Here, my use of 'thought' encompasses sensations, perceptions, memories, as well as reflections. This usage is common to Reid and his contemporaries.

${ }^{20}$ One shortcoming of the model discussed is that it is quite visiocentric; however, as Dyson and Quinlan (2003) note, lately there has been a trend to adopt and extend this model to other sense-modalities, with some promising results for hearing.

${ }^{21}$ Critics of FIT have argued that there is no fundamental distinction between registering features and binding them together; see, for example, Duncan and Humphreys (1989; 1992). Treisman $(1991 ; 1992)$ responded by pointing out that there is experimental evidence that a lot more time is spent registering the conjunctions of features than the features themselves.

${ }^{22}$ I will discuss R. M.'s case in more detail in the next section. For more on R. M., see Treisman (1999a).

${ }^{23}$ See, for instance EIP I.2, 43; EIP VI.6, 495.

${ }^{24}$ According to Treisman (1996: 171), there are at least seven types of binding problems that visual perception commonly solves. Property binding represents the core of the theory and is the version that Reid would have been mostly concerned with, so this is the only version of the binding problem that I will discuss.

25 The experiments described by Treisman and her colleagues have been contested on the basis of being difficult to find evidence of perception of unbound features. While Treisman and Gelade (1980) argued that the identification of features takes precedence over the localization of features (and thus that a certain feature can be unbound from its location), Sagi and Julesz (1985) argued for the opposite claim, and Green (1992) thought that there is an equality between the two types of operation. In response, certain refinements to the original FIT were proposed, and, by and large, psychologists seem to accept this model of visual perception, according to Wolfe (2003) and Chan and Hayward (2009).

${ }^{26}$ For a good review of the literature on motion tracking, see Scholl (2001). For a detailed discussion of some of the experiments conducted, see Pylyshyn (1989). 